\title{
Study on Regional Innovation Efficiency Based on DEA Three-stage Model-Take Ten cities in Shaanxi Province as an Example
}

\author{
Wang Meiting \\ International Business School of Shaanxi Normal University \\ Xi'an, 710100
}

\begin{abstract}
In order to further optimize the allocation of innovative resources, improve innovation efficiency, and fully tap regional development potential, this paper uses DEA's three-phase model to evaluate the innovation efficiency of ten cities in Shaanxi Province from the perspective of input and output, and on the other hand, it analyzes the changing trends and differences in time and regional innovation efficiency. The research results show that comprehensive technical efficiency is greatly affected by the scale effect, and the scaled efficiency is often underestimated in more developed cities such as $\mathrm{Xi}$ ' an. Overvalued cities are relatively underdeveloped, such as Ankang and Tongchuan. The influence of environmental factors is greater.
\end{abstract}

Keywords-Regional; DEA three-phase model; Innovation efficiency; Input and output

\section{INTRODUCTION}

Joseph Alois Schumpeter [1] first proposed the word "innovation". He used "innovation" to describe the reorganization of factors of production, and finally created new production capabilities through the integration of new production factors and production conditions in the production system. The report of the 19th CPC National Congress proposed that innovation is the primary driving force for development and the strategic support for the construction of a modern economic system. In the report, there were more than 10 times of Science and technology, and over 50 times of innovation. In response to national policies, provinces actively explore and implement innovation-driven development strategies and strive to build innovative provinces.

Chung [2] believes that in the 21st century an area wants to be invincible in competition, and the strength of innovation is the key. The development of a country is closely related to regional development. Regional development has become one of the important features of this century. Regarding the evaluation of regional innovation efficiency, generally, the innovation efficiency of computing input and output is mainly divided into two methods, parametric and non-parametric. One is to use the SFA model, such as Sun Wei et al [3]. To use the SFA model to compare the innovation efficiency of state-owned and non-state-owned enterprises in the high-tech industry in China. The advantage is that there is relevant theoretical support in the input-output relationship of the production function in the production process, and it can analyze the relevant factors affecting the quantitative differential efficiency. However, parametric model methods face the risk of model misconfiguration. Once the model is set incorrectly, estimation bias and inconsistency will lead to conclusions that are meaningless. Therefore, more scholars use the DEA method to determine the innovation efficiency of multi-input and multi-output. In terms of evaluation objects, they are oriented to the national level, such as Nasicrowski [4], Hakyeon [5], and Zhong Zuchang [6]. At the provincial level, such as Guo Shufen [7], Zhao Limin [8], etc. The research on innovation efficiency has attracted widespread attention from scholars. The research of these scholars provides a good theoretical reference and practical reference for regional development research, and provides a wealth of literature for future regional innovation efficiency research. However, in the existing research on regional innovation efficiency, the focus is on the relative macro level such as national or provincial level, involving less research on municipal level.

Nonparametric methods have unique advantages for innovative and complex production systems. It does not need to set inputs and outputs prior to a specific form of production. It can avoid model mis-selection caused by estimation bias. The weight of indicators is automatically calculated and determined by input and output data. The result is objective. Therefore, the DEA method has been widely used in innovation efficiency evaluation research. The traditional DEA method can measure the input-output efficiency of decision-making units, but ignores its internal management elements, external environmental elements and random error elements. The three-phase DEA method combines the advantages of parametric analysis and non-parametric analysis, places the inputs and outputs of the decision-making unit in the same environment, and makes the efficiency evaluation eliminate the interference of the external environment, and the result is more reliable. 


\section{REGIONAL INNOVATION EFFICIENCY INDICATOR SYSTEM AND EVALUATION MODEL}

Fried [9] pointed out that the original DEA model did not exclude external factors such as environmental factors and random noise, and the three-phase DEA model well overcomes this. In the first stage, the input-oriented BCC model is used. For any decision unit, the model can be expressed as:

$$
\begin{aligned}
& m \text { in } \theta-\varepsilon\left(\hat{e}^{T} S^{-}+e^{T} S^{+}\right) \\
& \text {s.t. }\left\{\begin{array}{l}
\sum_{j=1}^{n} X_{j} \lambda_{j}+S^{-}=\theta X_{0} \\
\sum_{j=1}^{n} Y_{j} \lambda_{j}-S^{+}=Y_{0} \\
\lambda_{j} \geq 0, S^{-}, S^{+} \geq 0
\end{array}\right. \\
& S_{n i}=f\left(Z_{i} ; \beta_{n}\right)+v_{n i}+\mu_{n i} ; i=1,2, \cdots, I ; n=1,2, \cdots, N
\end{aligned}
$$

Among them, $j=1,2, \cdots, n$ is the decision-making unit , $X, Y$ is input and output vector. The DEA model is essentially a linear programming problem.

\begin{tabular}{|c|c|c|c|}
\hline $\begin{array}{l}\text { First-level } \\
\text { indicators }\end{array}$ & Second-level indicators & Measurable indicators & $\begin{array}{l}\text { Meaning and interpretation of } \\
\text { indicators }\end{array}$ \\
\hline \multirow{3}{*}{ Investment } & Labor input & R\&D personnel & \\
\hline & Capital investment & Internal R\&D expenses & \\
\hline & Technical input & $\begin{array}{l}\text { The number of patent } \\
\text { applications in the previous } \\
\text { year }\end{array}$ & \\
\hline \multirow{2}{*}{ Outputs } & $\begin{array}{l}\text { Technological } \\
\text { Achievements }\end{array}$ & $\begin{array}{l}\begin{array}{l}\text { Number } \\
\text { applications }\end{array} \\
\end{array}$ & \\
\hline & Business transformation & New product sales revenue & \\
\hline \multirow{4}{*}{$\begin{array}{l}\text { Environmental } \\
\text { variables }\end{array}$} & $\begin{array}{lcc}\text { Urban and city } \\
\text { development level }\end{array}$ & Per capita GDP & \multirow{4}{*}{$\begin{array}{l}\text { "separation hypothesis" is an } \\
\text { important basis for selecting } \\
\text { environmental variables, ie those } \\
\text { that are not subjectively } \\
\text { controlled by the sample but may } \\
\text { affect the efficiency of the area. }\end{array}$} \\
\hline & Policy aspects & $\begin{array}{l}\text { Proportion of } \begin{array}{r}\text { financial } \\
\text { science and technology } \\
\text { appropriation to financial } \\
\text { expenditure }\end{array} \\
\end{array}$ & \\
\hline & Industrial structure level & $\begin{array}{lr}\text { Large and medium- } & \text { sized } \\
\text { industrial } & \text { enterprises } \\
\text { Quantity } & \\
\end{array}$ & \\
\hline & Quality of workers & $\begin{array}{l}\text { Universidad } \quad \text { College } \\
\text { Students per 10,000 Quantity }\end{array}$ & \\
\hline
\end{tabular}

If $\theta=1, S^{+}=S^{-}=0$, the decision unit DEA is valid; valid;

If $\theta=1, S^{+} \neq 0$, 或 $S^{-} \neq 0$, the decision unit weak DEA is

If $\theta<1$, the decision unit is non-DEA valid.

The second stage decomposes the slack variables into environmental components, manages the three effects of inefficiency and statistical noise, and eliminates the effects of random noise by the SFA regression function:

TABLE I

REGIONAL INNOVATION EFFICIENCY INDEX SYSTEM 


\section{B. Data Sources and Descriptions}

The "12th Five-Year Plan" period is a very special period and is the key point for the overall innovation of China's development. Especially after the Nineteenth National Congress, economic development became more inseparable from the drive of innovation. Innovation-driven strategic positions have become increasingly significant and have gradually become an important means of promoting economic and social development. Therefore, this paper selects the innovation input data and output data of 10 cities in Shaanxi Province from 2011 to 2015 to compare and analyze the innovation efficiency. The data comes from China Urban Statistical Yearbook and Shaanxi Science and Technology Statistical Yearbook. Data information is accurate and reliable, records are standardized, and representation is extremely strong.

\section{MEASUREMENT OF REGIONAL INNOVATION EFFICIENCY IN SHAANXI PROVINCE}

\section{A. BCC Model Results}

In the first phase of DEA analysis, the traditional BCC model was used to analyze the technical efficiency, pure technical efficiency, and scale efficiency of 10 cities in Shaanxi Province from 2011 to 2015. Figure 1 presents the evolution of innovation efficiency in the tenth city of Shaanxi Province during the first phase of DEA 2011-2015 (before adjustment). As shown in Figure 1, the innovation efficiency in Xianyang City and Hanzhong City increased significantly from 2011 to 2015. Apart from Shangluo City and Ankang City, the innovation efficiency of the eight other cities in Shaanxi Province fluctuate widely.

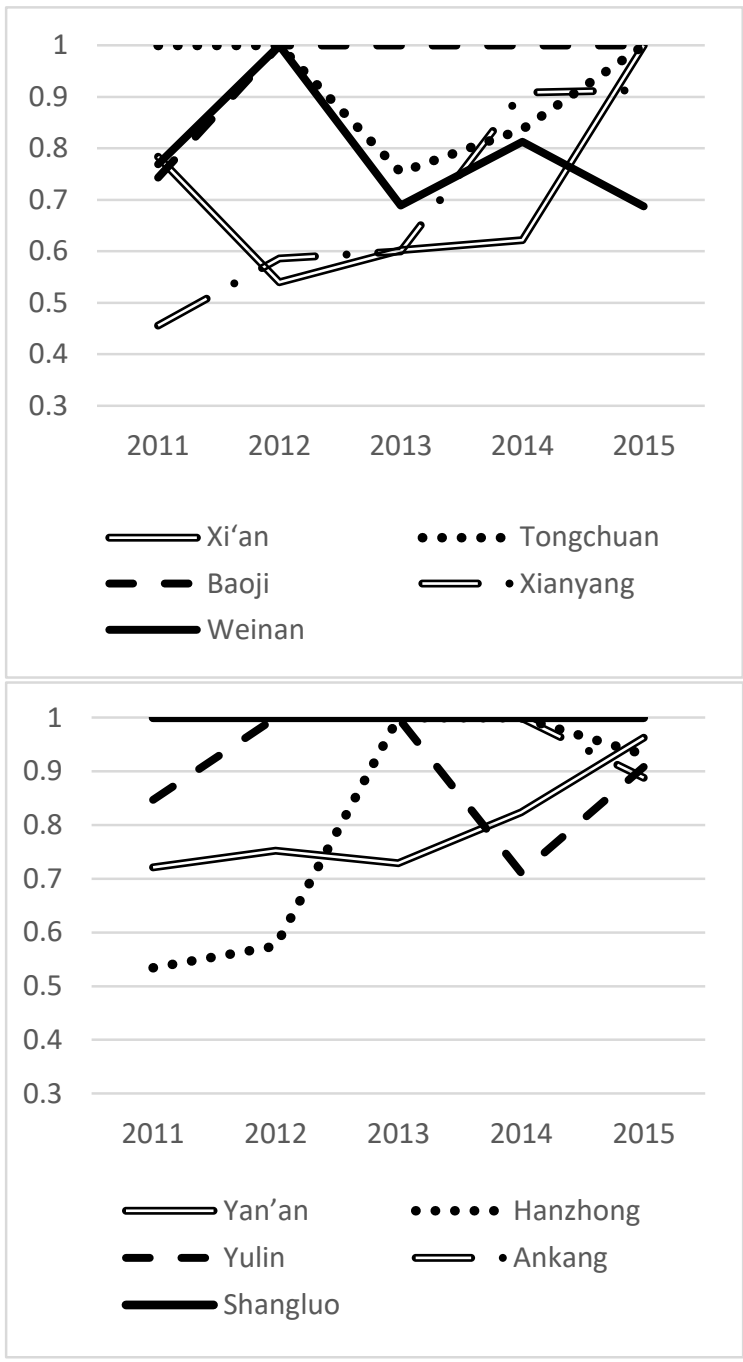

Fig. 1 Evolution Trends of Innovation Efficiency in Shaanxi, 2011-2015 (first phase)

\section{B. SFA-like stochastic frontier analysis}

In the second phase of DEA-SFA-like stochastic frontier analysis, the first three types of input variables R\&D full-time staff equivalents, R\&D expenditures internal expenditures, the previous year's patent applications as an explanatory variable of the function. selecting Per capita GDP , Proportion of financial science and technology appropriation to financial expenditure , Large and medium-sized industrial enterprises ,Quantity Universidad College Students per 10,000 Quantity as environmental variables to study their effects on the three input slack variables. When the regression coefficient is greater than 0 , it means that increasing the explanatory variable will not be conducive to reducing the amount of slack, resulting in serious waste, and vice versa. When it is less than 0 , it means that increasing the explanatory variable can improve the utilization of resources and enhance the R\&D and innovation effectiveness. The second phase was calculated using Frontier4.1 software. Taking 2015 as an example, the analysis results are shown in Table 2 . 


\begin{tabular}{llll}
\hline constant items & 856.22 & -1.32 & 24.45 \\
Per capita GDP & -0.06 & 0.00 & -0.01 \\
$\begin{array}{l}\text { Proportion of financial science and technology } \\
\text { appropriation to financial expenditure }\end{array}$ & -113.76 & 8.60 & 404.47 \\
$\begin{array}{l}\text { Large and medium- sized industrial enterprises } \\
\text { Quantity }\end{array}$ & 22.65 & -0.03 & -0.35 \\
$\begin{array}{l}\text { Universidad College Students per 10,000 } \\
\text { Quantity } \\
\text { sigma-squared }\end{array}$ & -2.28 & -0.02 & -0.85 \\
gamma & 843850.51 & 8.98 & 22802.66
\end{tabular}

Through the analysis of the forthcoming SFA-like frontier model in the second stage, the adjusted input value is calculated. The adjustment formula is as follows:

$$
X_{n i}^{A}=X_{n i}+\left[\max \left(f\left(Z_{i} ; \hat{\beta}_{n}\right)\right)-f\left(Z_{i} ; \hat{\beta}_{n}\right)\right]+\left[\max \left(v_{n i}\right)-v_{n i}\right]
$$$$
\boldsymbol{E}(\mu \mid \varepsilon)=\sigma_{*}\left[\frac{\phi\left(\lambda \frac{\varepsilon}{\sigma}\right)}{\Phi\left(\frac{\lambda \varepsilon}{\sigma}\right)}+\frac{\lambda \varepsilon}{\sigma}\right]
$$

Among them, $X_{n i}^{A}$ is the adjusted input. $X_{n i}$ is the input before the adjustment. $\left[\max \left(f\left(Z_{i} ; \hat{\beta}_{n}\right)\right)-f\left(Z_{i} ; \hat{\beta}_{n}\right)\right]$ is the adjustment of the external environmental factors. $\left[\max \left(v_{n i}\right)-v_{n i}\right]$ places all decision units on the same level of luck.

First, separate management inefficiency terms, and management inefficient separation formulae, according to the idea of Jondrow [10], the separation formula is as follows: among them $\sigma_{*}=\frac{\sigma_{\mu} \sigma_{v}}{\sigma}, \sigma=\sqrt{\sigma_{\mu}{ }^{2}+\sigma_{v}{ }^{2}} \quad \lambda=\sigma_{\mu} / \sigma_{v}$

The second step is to calculate the random error term as follows:

$$
E\left[v_{n i} \mid v_{n i}+\mu_{n i}\right]=s_{n i}-f\left(z_{i} ; \beta_{n}\right)-E\left[u_{n i} \mid v_{n i}+\mu_{n i}\right]
$$

Taking 2015 as an example, the final adjusted input is shown in Table 3: 
INVESTMENT VALUES BeFORE AND AFTER AdJUSTMENT IN TEN CitIES IN SHAANXI PROVINCE, 2010-2015

\begin{tabular}{|c|c|c|c|c|c|c|c|c|}
\hline \multirow{2}{*}{$\begin{array}{l}\text { Time } \\
\text { period }\end{array}$} & \multirow{2}{*}{ No. } & \multirow{2}{*}{ city } & \multicolumn{2}{|c|}{$\begin{array}{l}\text { R\&D full-time staff } \\
\text { equivalent }\end{array}$} & \multicolumn{2}{|c|}{$\begin{array}{l}\text { R\&D expenditure internal } \\
\text { expenditure }\end{array}$} & \multicolumn{2}{|c|}{$\begin{array}{l}\text { Patent application } \\
\text { amount in the previous } \\
\text { year }\end{array}$} \\
\hline & & & $\begin{array}{l}\text { Original } \\
\text { input }\end{array}$ & $\begin{array}{l}\text { Adjusted } \\
\text { input }\end{array}$ & $\begin{array}{l}\text { Original } \\
\text { input }\end{array}$ & $\begin{array}{l}\text { Adjusted } \\
\text { input }\end{array}$ & $\begin{array}{l}\text { Original } \\
\text { input }\end{array}$ & $\begin{array}{l}\text { Adjusted } \\
\text { input }\end{array}$ \\
\hline \multirow{10}{*}{2015} & 1 & Xi'an & 67229 & 71042.68 & 303.71 & 308.63 & 43320 & 43595.50 \\
\hline & 2 & Tongchuan & 137 & 4067.58 & 0.3 & 5.42 & 320 & 636.50 \\
\hline & 3 & Baoji & 7583 & 11141.25 & 29.92 & 33.78 & 2133 & 2369.07 \\
\hline & 4 & Xianyang & 7110 & 7168.32 & 11.22 & 16.68 & 2049 & 2232.54 \\
\hline & 5 & Weinan & 3520 & 5941.83 & 17.3 & 17.30 & 1886 & 1886.00 \\
\hline & 6 & Yan'an & 834 & 5889.86 & 5.36 & 11.61 & 847 & 1296.84 \\
\hline & 7 & Hanzhong & 2850 & 6305.17 & 10.88 & 18.35 & 1399 & 1784.63 \\
\hline & 8 & Yulin & 1062 & 4930.63 & 2.74 & 8.19 & 1363 & 1757.70 \\
\hline & 9 & Ankang & 662 & 4408.51 & 1.16 & 4.99 & 465 & 698.76 \\
\hline & 10 & Shangluo & 428 & 4181.56 & 1.63 & 5.53 & 1536 & 1761.49 \\
\hline
\end{tabular}

\section{Adjusted Innovation Efficiency Analysis}

In the final stage of the DEA analysis, similar to the first stage method, through the adjusted data, comprehensive technical efficiency, the pure technical efficiency and scale efficiency of ten cities in Shaanxi Province are recalculated. The results are shown in the Table 4.

TABLE IV Average EfFiciency of 10 Cities, ShaAnXi Province, 2010-2015 (ADJUSTED Results)

\begin{tabular}{lllll}
\hline No. & city & Technical Efficiency & $\begin{array}{l}\text { Pure } \\
\text { Efficiency }\end{array}$ & $\begin{array}{l}\text { Technical } \\
\text { Efficiency }\end{array}$ \\
\hline 1 & Xi'an & 0.9558 & 1 & 0.9558 \\
2 & Tongchuan & 0.5528 & 1 & 0.5528 \\
3 & Baoji & 1 & 1 & 1 \\
4 & Xianyang & 0.8144 & 0.8798 & 0.9258 \\
5 & Weinan & 0.9032 & 0.962 & 0.9368 \\
6 & Yan'an & 0.7524 & 0.8772 & 0.8492 \\
7 & Hanzhong & 0.8166 & 0.8888 & 0.9244 \\
8 & Yulin & 0.9028 & 0.9352 & 0.9652 \\
9 & Ankang & 0.5134 & 0.9402 & 0.5416 \\
10 & Shangluo & 0.9506 & 0.9754 & 0.9732
\end{tabular}

IV. ANALYSIS OF REGIONAL INNOVATION EFFICIENCY IN SHAANXI PROVINCE

After eliminating random interference and environmental factors in the third phase, the cities in the frontier of technological efficiency, pure technological efficiency, and scale efficiency from 2011 to 2015 are Baoji and Xi'an, indicating that the resource allocation of these cities is relatively reasonable and various technological innovations have been achieved. Investment has played a good role, the level of technology has been brought to a higher level, innovation efficiency has been relatively advanced, and its regional production value is also at the forefront. It is worth noting that the pure technical efficiency, scale efficiency, and technical efficiency of Shangluo City are also at a relatively high level, which is inconsistent with our traditional understanding. This is mainly because "economy" and "technology" are all studying efficiency issues. However, it should be pointed out that the former is based on economic benefits, that is, in a project, not only the input of labor and 
capital, but also the cost of labor, the price of equipment, etc. The cost-effectiveness can not be ignored. The latter considers its feasibility only from a technical point of view. Technical efficiency does not mean that it is economically efficient. It focuses more on whether the investment in labor and capital is effective and does not focus on the price of its production factors. Therefore, high technical efficiency and high cost-effectiveness are not in an equal position.

Figure 2 further shows the evolution of innovation efficiency in 10 city of Shaanxi Province in the third phase of DEA from 2011 to 2015 (after adjustment). As can be seen from Figure 2, the innovation efficiency of Tongchuan City and Ankang City was significantly behind in 2011-2015, and the innovation efficiency of Weinan City continued to decline.

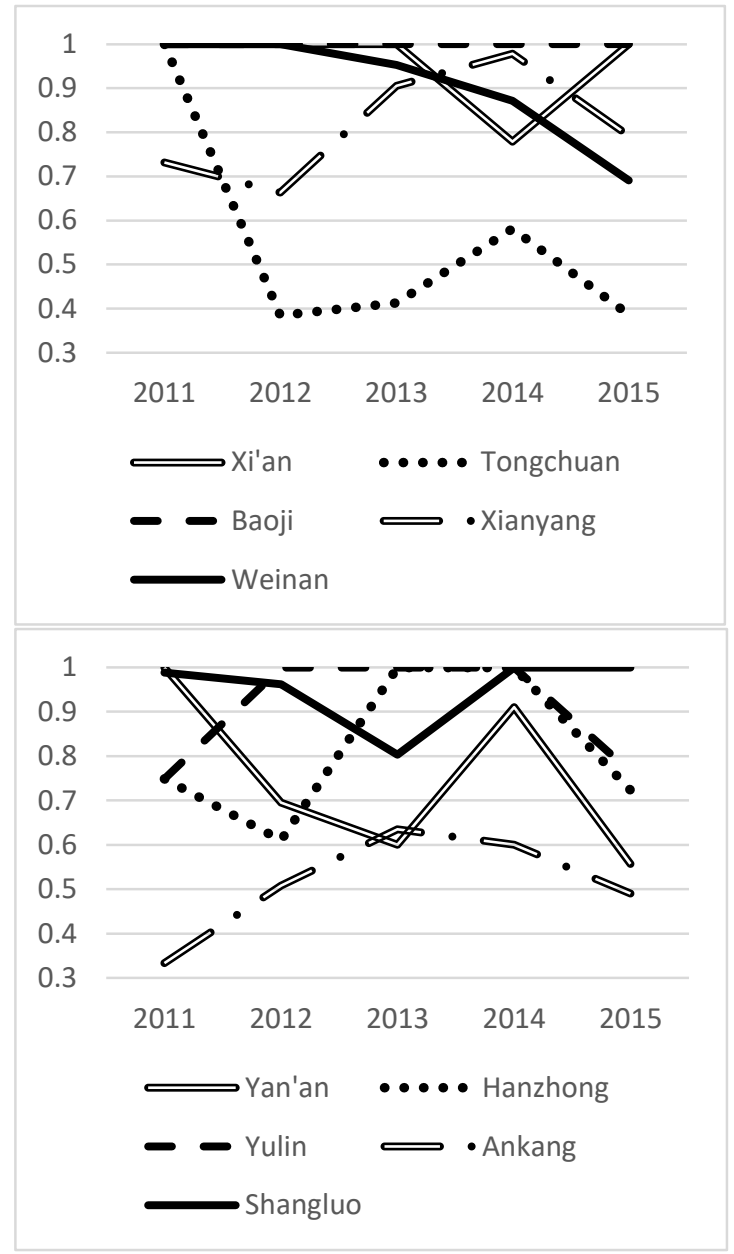

Fig. 2 Evolution Trend of Innovation Efficiency in Shidi City, Xi'an, 2011-2015 (Phase 3)

\section{V.CONCLUSIONS AND SUGGESTIONS}

In order to reflect the innovation efficiency of ten cities in Shaanxi Province, this paper uses a three-phase DEA model to evaluate the innovation efficiency of ten cities in Shaanxi Province from 2011 to 2015 . The results of the research show that after removing the interference of random factors and environmental factors, the overall technical efficiency, pure technical efficiency, and scale efficiency have changed in most cities. Comprehensive technical efficiency is greatly influenced by economies of scale. Scale efficiency is often underestimated in more developed cities, such as Xi'an. Overvalued cities are relatively underdeveloped, such as Ankang and Tongchuan. These two types of cities are affected by environmental factors. From the perspective of innovation-driven perspective, in order to further optimize the allocation of innovative resources and improve the efficiency of innovation, the following countermeasures and recommendations are proposed based on this:

According to the data of 2015, the scale returns of 7 cities in 10 cities of Shaanxi Province are increasing, indicating that the improvement of regional innovation efficiency can be achieved by increasing the scale. As can be seen from the analysis, most of Shaanxi Province's technological innovation is still underinvested. In order to increase the efficiency of technological innovation, the increase in investment in science and technology has become particularly important. Innovation-driven development strategy is an important strategic approach to building an innovative country. It should continue to increase investment in capital and technology, guide the entire society to innovate, and turn input resources into benefits. Whether national scientific and technological achievements have been further enhanced or whether it has reached a higher level in the country or even in the world, it is inseparable from the investment in scientific and technological resources. Although science and technology have developed rapidly in Shaanxi Province, the proportion of science and technology expenditures at the same level in some cities and regions remains low, and some even decline. This situation is partly due to the fact that the level of science and technology investment in some regions is indeed low, and on the other hand, some cities have high technology investment, but the growth rate of investment is still lower than the growth rate of fiscal expenditure. The steady growth mechanism for local financial technology investment needs to be strengthened. The task of promoting cities to strengthen scientific and technological work remains arduous. It is necessary to strengthen research on science and technology policies in the new situation.

When formulating regional economic development strategies, Shaanxi Province must fully consider the different characteristics of urban economic development. For the under-invested cities, in order to effectively promote development, it is necessary to increase investment in infrastructure, public education and scientific research. For cities with insufficient technological progress, technology transfer in developed cities is particularly important. Technology transfer will improve the speed of technological progress in backward cities. In addition, various policies will be needed to promote the optimization of urban innovation 
resource allocation, increase innovation efficiency, and enhance innovation capabilities. Constantly deepen the strategic significance of innovation-driven development.

\section{REFERENCES}

[1] Joseph Bearbit. Economic Development Theory [M]. Commercial Press, 2000-03-00 11-47.

[2] Chung S. Building a national innovation system through regional innovation systems [J]. Technovation, 2002, (22): 485-491.

[3] Sun Wei, Wang Jiuyun, Cheng Liwei. The Spillover Effect of FDI Quality on the Efficiency of Independent Innovation in High-tech Industries_-An Empirical Study Based on the Ownership Structure of Chinese Enterprises [J]. Research Management, 2011, 32(8): 57-66. (In Chinese)

[4] Nasierowski W, Arcelus F.J, Interrelationships Among the Elements of National Innovation Systems: A Statistical Evaluation [J], European Journal of Operational Research, 1999, 119: 235-253.

[5] Hakyeon L, Yongtae P, Hoogon C. Comparative evaluationof performance of national $\mathrm{R} \& \mathrm{D}$ programs with heterogeneousobjectives: A DEA approach [J]. European Journal of Opera- tional Research, 2009, 196(3): 847-855.

[6] Zhong Zuchang. Research on the Structural Characteristics and Convergence of National Innovation Efficiency: Empirical Analysis Based on OECD Countries and China [J]. Science of Science and Management of S. \&gt;, 2012, 33(2): 22-29. (In Chinese)

[7] Guo Shufen, Zhang Jun. A comparison of technological innovation efficiency and input redundancy in 31 provinces and cities in China [J].Science Research Management, 2018, 39(04):55-63. (In Chinese)

[8] Zhao Limin, Liu Shuai. The Evaluation of Output Efficiency of High-tech Industry in the Central Region and Inter-provincial Differences: An Analysis Based on the Three-phase Panel DEA [J].Scientific Management Research, 2017, 35(06):70-73. (In Chinese)

[9] Fried H O, Schmidt S S, Yaisawarng S. Incorporating the Operating Environment Into a Nonparametric Measure of Technical Efficiency [J]. Journal of Productivity Analysis, 1999, 12(3): 249-267.

[10] Jondrow J, Lovell C. A. K, Materov I. S. Et al. On the Estimation of Technical Inefficiency in the Stochastic Frontier Production Function Mode [J]. Journal of Econometrics, 1982, 19(S2-3): 233-238. 